\title{
Implications of Global Peak Population for Canada's future: Northern, rural, and remote communities
}

\author{
Martin Cooke ${ }^{1}$
}

\begin{abstract}
The broad demographic changes that are affecting the Canadian population, including population aging and changes to immigration, will not have the same impact or implications in all places across the country. For communities in the North and rural and remote communities in the South, the patterns of demographic change might be quite different from those faced by cities. There is also considerable diversity among these non-urban areas. Non-urban hinterlands that are within commuting distance of cities (high Metropolitan Influence) have been growing, with some being reclassified as parts of urban agglomerations. Population change in rural areas that are outside of urban influence is more closely related to employment dynamics in particular sectors, especially agriculture and resource extraction. Populations of many of those communities have been declining and aging, due to out-migration of young adults and a lack of immigration. In the North, where populations are younger, resource development has meant rapid change to Northern communities and cultures. Current challenges for Northern, rural, and remote communities include potential labour force skills shortages and adapting infrastructure to a changing population, in the context of difficult geography. Future issues related to population change have implications for social cohesion. In the North, there is a risk of widening socio-economic inequality, particularly between Indigenous and non-Indigenous populations. In the South, disparities in lifestyles and labour force experiences between rural and urban populations might also grow. Recommendations for knowledge development include more research on the effective recruitment and retention of professionals, including immigrants, in these areas, as well as better sources of data on Northern populations.
\end{abstract}

Keywords: 1, 2, 3, 4, 5 .

\section{Résumé}

The broad demographic changes that are affecting the Canadian population, including population aging and changes to immigration, will not have the same impact or implications in all places across the country. For communities in the North and rural and remote communities in the South, the patterns of demographic change might be quite different from those faced by cities. There is also considerable diversity among these non-urban areas. Non-urban hinterlands that are within commuting distance of cities (high Metropolitan Influence) have been growing, with some being reclassified as parts of urban agglomerations. Population change in rural areas that are outside of urban influence is more closely related to employment dynamics in particular sectors, especially agriculture and resource extraction. Populations of many of those communities have been declining and aging due to out-migration of young adults and a lack of immigration. In the North, where populations are younger, resource development has meant rapid change to Northern communities and cultures. Current challenges for Northern, rural and remote communities include potential labour force skills shortages and adapting infrastructure to a changing population, in the context of difficult geography. Future issues

1. Department of Sociology and Legal Studies and School of Public Health and Health Systems, University of Waterloo, 200 University Avenue West, Waterloo, ON N2L 3G1; email: cooke@uwaterloo.ca. 
related to population change have implications for social cohesion. In the North, there is a risk of widening socioeconomic inequality, particularly between Indigenous and non-Indigenous populations. In the South, disparities in lifestyles and labour force experiences between rural and urban populations might also grow. Recommendations for knowledge development include more research on the effective recruitment and retention of professionals, including immigrants, in these areas, as well as better sources of data on Northern populations.

Mots-clés : 1, 2, 3, 4, 5.

Popular imagery often emphasizes Canada's non-urban landscapes, including agrarian scenes, picturesque maritime towns and northern wilderness. As we know, however, the majority of Canadians are city dwellers, with 83 per cent living in cities of 10,000 or more in 2016, and two-thirds of the population clustered near the southern border (Statistics Canada 2017a). Although definitions of "urban" vary internationally, this makes Canada among the most urbanized in the world, certainly among highly developed countries (Statistics Canada 2012).

The dynamics of population change and the implications of that change are somewhat different for rural areas and small towns, and communities in the North, compared to urban centres in the South. Although the proportion of Canadians living in rural settings has been declining for a long time, the size of the rural population has nonetheless been recently increasing. In the 2016 census, the total rural and small town population including the Territories was 5,918,771 people, an increase of 1.4 per cent since 2011 (Bollman 2017). This overall growth in the rural population masks a great deal of regional diversity, but there are some commonalities among these communities, particularly in the challenges that are presented by the broader demographic processes of population aging, slowing population growth, and changing migration patterns.

In this report, we briefly describe the main aspects of recent demographic change in rural and remote communities in southern Canada and in the North, and the emerging issues and future challenges that we can expect. Space does not permit a thorough consideration of the full diversity of community types and regional differences across the country. In particular, First Nations reserve communities vary greatly in terms of size, proximity to urban areas, and demography (Cooke and O'Sullivan 2015), and so are not specifically addressed here.

\section{Demographic changes in rural areas in the South}

Regional differences in the ways that southern rural populations are changing in Canada are related to the relationships between rural areas and urban systems. Overall, the population in Canadian rural areas and small towns, defined as areas that are neither Census Metropolitan Areas (CMAs) nor Census Agglomerations (CAs), ${ }^{2}$ has been fairly stable over the past several census periods, experiencing either small amounts of growth or decline (Bollman 2017). However, assessing the overall pattern of demographic change is complicated by the reclassification of formally non-urban areas as "urban," as well as by the regional diversity of rural areas. Ontario, for example, saw growth in its rural area and small town population of 2.6 per cent between 2011 and 2016, while the rural area and small town population of Nova Scotia fell by 2.1 per cent in this period (Bollman 2017).

2. Census Metropolitan Areas (CMAs) are one or more municipalities with a total population of at least 100,000, with 50,000 or more in a single urban core. Census Agglomerations (CAs) have an urban core population of at least 10,000 (Statistics Canada 2017b). 
These regional differences are no doubt related to different economic activities in the regions, but they also reflect different aspects of rural-urban systems. It is important to distinguish between areas that are "rural" as defined by their own population density but which are within commuting distance of larger urban areas, and rural areas that are not within the "shadows" of urban areas. Those that are closer to CMAs or CAs (strong and moderate Metropolitan Influence Zones ${ }^{3}$ ) have grown rather consistently in census periods from 1986-91 to 2011-16, with a 3.4 per cent increase in the most recent period (Bollman 2017). This has resulted in the redefinition of boundaries, and redefinition of some of these former hinterland areas as now being within urban agglomerations (Bollman 2017) — as in the Windsor-Toronto-Montreal corridor, for example. For these near-urban rural areas (with high Metropolitan Influence), the factors underlying population change might be more similar to those of their larger urban neighbours. They tend to have more diverse employment and higher average educational attainment than other rural areas, owing to the possibility of commuting, as well as being sites for employment outside of the resource industries (Bollman and Alasia 2012; Lauzon et al. 2015). Some of these areas have been affected by changes to those sectors, such as the recent reductions in manufacturing employment in Ontario (Lauzon et al. 2015).

On the other hand, rural areas that are outside of the influence of large metropolitan areassuch as those in the Prairie Provinces or Atlantic region-have experienced more consistent population decline (Bollman 2017). These areas are more likely to have economies that are tied tightly to resource sectors, and recent demographic changes can be related to sectoral economic changes. One example is the increase in the size of farming operations over the past several decades, resulting in fewer entrants to that industry and an older average age of farm operators (Alasia 2010; Beaulieu 2014).

Despite the diversity among rural areas in the South, there are some generalizations that can be made regarding recent demographic changes. Overall, these areas are either growing slowly or experiencing population decline, and have an older average age, owing to both out-migration of young people (Bollman and Clemenson 2008; Moazzami 2013) and a lack of immigrant settlement, as the large majority of immigrants to Canada continue to land in the CMAs (Beshri and He 2009; Statistics Canada 2017b). Moreover, those immigrants that have recently settled in rural areas have tended to be from western and northern Europe and the United States, rather than from Asia or Africa (Beshri and He 2009). Rural areas vary in the degree to which their economies are based on agriculture or resource extraction, but in general they have lower average educational attainment, lower average employment income, and higher unemployment rates than do urban areas (Lauzon et al. 2015; Moazzami 2013).

\section{Demographic change in Northern communities}

Communities in the North are experiencing different demographic dynamics than are rural areas in the South. Natural increase, due to higher fertility than the Canadian average-particularly in Nunavut (Statistics Canada 2017d) - means that the population of the North is younger than the overall Canadian population, and it is growing (Milan 2011). However, despite the energy and resource development that has occurred in the North in recent decades (Standing Committee on Natural Resources 2012), there has been net out-migration from the Territories every year since the 1980s. This net loss of migrants conceals a fair amount of in-migration to the North (Sergerie

3. Metropolitan Influence Zones (MIZ) are a classification of non-urban places on the basis of the percentage of the employed population that commutes to work in the core of a CA or CMA (Statistics Canada 2017b). 
2016). It also does not consider the "rotational" workforce of "fly-in/fly-out" workers who live in other provinces or territories but work in the North (Conference Board of Canada 2016).

As in the South, there are regional differences between the northern territories. Both Yukon and Nunavut have been growing more quickly than the total Canadian population over the past decade; Nunavut had the highest growth rate of the provinces and territories between 2011 and 2016 (12.7 per cent), and Yukon had the highest growth rate between 2006 and 2011 (11.6 per cent) but grew more slowly between 2011 and 2016 (5.8 per cent). The population of the Northwest Territories, however, grew at only 0.8 per cent between 2011 and 2016 (Statistics Canada 2017a).

\section{Emerging issues in Southern rural areas and Northern communities}

Despite the differences between rural areas in the South and northern communities, and the regional differences within these community types, the above-described demographic processes do present some common emerging challenges in the short and medium terms.

\section{Continuing skills shortages in particular industries}

There is academic disagreement about the degree to which population aging might lead to widespread skills shortages, or whether the labour markets will adjust in various ways (Creedy and Guest 2013). Nonetheless, rural and remote communities in both the South and Northern regions will likely face shortages of skills in particular occupations and industries. Overall, this can be due to an older age structure of some occupations and industries, coupled with high barriers to younger entrants. One example is farming, where the proportion of enterprises in which the oldest operator was at least 55 years old in 2011 was 55 per cent, and where the costs of entry and potential risk of price instability in some farm products are significant barriers for new farmers (Beaulieu 2014). This occupation is also likely to include longer educational requirements, as well as large numbers of retirements expected in the short term (McMullin et al. 2008). Potential skills shortages could be compounded by the difficulties already experienced in recruiting and retaining professionals in industries such as health care (Hanlon and Halseth 2005), and difficulties in attracting and retaining immigrants with skills to these areas (Simard 2009).

\section{Infrastructure needs in response to changing population, in a difficult geography}

The growth and age composition of the population in northern and remote communities will lead to continuing challenges for infrastructure such as roads, housing, and social and health service provision. This will likely be different in the North and in rural communities in the South. For many non-Aboriginal rural and remote communities in the South that do not have labour in-migration, infrastructure associated with population aging is an emerging issue. In these communities, in which out-migration by younger people has led to an older remaining rural population, needs associated with maintaining seniors' health and providing support as they age in place might pose a significant burden on communities. Other communities, particularly in the North, will experience challenges associated with a young and growing population. In both types of community, some needs, such as that for transportation or mobility assistance, might be especially exacerbated by remoteness and difficult geography. 


\section{Future challenges}

In the longer term, three interrelated future challenges are important for both Northern and Southern rural communities in Canada.

\section{Rapid social and cultural change in the North}

The North has seen dramatic changes over the past several decades. These have involved rapid modernization and development, and have meant the importation of new lifestyles and cultures (Southcott 2013). This has been especially devastating for Inuit and other Indigenous communities, which have seen cultural and geographic displacement affect their social and physical well-being (Richmond and Ross 2009). As resource-based economic activity continues to increase, there will likely be more in-migration of non-Indigenous people to the North, at least on a temporary basis. This might also include higher international migration, leading to challenges related to immigrant integration (Simard 2009; Yoshida and Ramos 2013).

\section{Increasing income and social inequality}

Rising income inequality has been identified as a major social policy problem. The changes that we have described have the potential to exacerbate inequalities in at least two ways.

First, it seems likely that socio-economic inequality will increase within the North. Already in 2011, the census divisions with the highest median incomes and those with the lowest median incomes were both found in the North (Sisco and Stonebridge 2010). This reflects the disparity between communities that have access to resources development opportunities and those that do not. This between-community inequality seems likely to increase, as might the inequality between those with the human capital to find employment in these resource sectors and those that do not. In particular, it seems that integrating the young and growing Indigenous population into the economy will be a major challenge, with the potential for disparities between Indigenous and non-Indigenous northerners to widen.

Second, in the case of southern rural communities, the disparity between rural areas and urban ones within the same regions is at risk of widening. As described above, rural communities in the South tend to have lower average educational attainment and higher unemployment. As farming, manufacturing, and other resource industries continue to require less labour, due in part to automated processes, the disparity between these areas and urban ones might widen, in terms of their residents' employment and income trajectories (Lauzon et al. 2015).

\section{Lower social cohesion}

These two dynamics, increasing inequality and rapid cultural change, might have implications for social cohesion in Canada. High migration, especially short-term labour migration, might itself lead to reduced social cohesion or social capital in Northern communities (Cooke and O'Sullivan 2015). This might exacerbate other dimensions of social cohesion, including Aboriginal-nonAboriginal relations. In the South, an increasing differentiation of experiences between rural and urban residents might continue to lead to political differences, with implications for federal and regional electoral politics (Speers and Jivani 2017). 


\section{Expanding our knowledge base}

Some areas require further research or knowledge translation efforts, and better data. This is particularly the case for the North. We offer some examples below.

\section{Research on effective recruitment and retention of professionals}

The problem of recruiting and retaining professionals to work in remote areas is not a new one, although there are unique challenges in both Northern and rural communities. There has not been a systematic assessment of best practices for recruitment and retention, however, especially one specific to a Northern context.

\section{Better data on the Northern populations}

Although there are more data about the North regularly available than before, not all Statistics Canada surveys collect data, or sufficient data, in the North. For example, the new Longitudinal and International Survey on Adults, which will allow the examination of long-term employment and work trajectories, includes neither the Territories nor the northern areas of provinces (Statistics Canada 2015).

\section{References}

Alasia, A. 2010. Population change across Canadian communities, 1981 to 2006: The role of sector restructuring, agglomeration, diversification and human capital. Rural and Small Town Canada Analysis Bulletin 8(4):1-32.

Beaulieu, M.S. 2014. Demographic changes in Canadian agriculture, in Canadian Agriculture at a Glance. Cat. No. 96-325-X. No 001. Ottawa: Statistics Canada.

Beshri, R., and J. He. 2009. Immigrants in rural Canada: 2006. Rural and Small Town Canada Analysis Bulletin 8(2).

Bollman, R.D. 2017. Rural Demography Update 2016. Guelph, ON: Rural Ontario Institute.

Bollman, R.D., and A. Alasia. 2012. A profile of self-employment in rural and small town Canada: Is there an impending retirement of self-employed business operators? Rural and Small Town Canada Analysis Bulletin 9(1):1-37.

Bollman, R.D., and H.A. Clemenson. 2008. Structure and change in Canada's rrural demography: An update to 2006. Rural and Small Town Canada Analysis Bulletin 7(7):1-27.

Conference Board of Canada. 2016. Northwest Territories Labour Market Forcast and Needs Assessment. Ottawa: Conference Board of Cananda.

Cooke, M., and E. O'Sullivan. 2015. The impact of migration on the First Nations community wellbeing index. Social Indicators Research 122(2):371-89.

Creedy, J., and R. Guest. 2013. Population Ageing, Pensions, and Growth: Intertemporal Trade-Offs and Consumption Planning. Cheltenham (UK): Edward Elgar.

Hanlon, N., and G. Halseth. 2005. The greying of resource communities in northern British Columbia: Implications for health care delivery in already underserviced communities. The Canadian Geographer/Le Geographe canadien 49(1):1-24. 
Lauzon, A., R. Bollman, and B. Ashron. 2015. Introduction, in State of Rural Canada Report. Regina: Canadian Rural Revitalization Foundation.

McMullin, J.A., M. Cooke, and T. Tomchick. 2008. Work and retirement in Canada: Policies and prospects, in Ageing Labour Forces: Promises and Prospects, edited by P. Taylor. Cheltenham (UK): Edward Elgar, p. 62-83.

Milan, A. 2011. Age and Sex Structure: Canada, Provinces, and Territories, 2010. Ottawa: Statistics Canada.

Moazzami, B. 2013. Introduction: Strengthening rural Canada: Fewer \& older: Population and demographic challenges across rural Canada; A pan-Canadian report. Adult Learning, Literacy, and Essential Skills Program. http://strengtheningruralcanada.ca/file/Fewer-Older-Population-andDemographic-Challenges-Across-Rural-Canada.pdf; retrieved 16 January 2018.

Richmond, C.A., and N.A. Ross. 2009. The determinants of First Nation and Inuit health: A critical population health approach. Health \& Place 15(2):403-11.

Sergerie, F. 2016. Internal migration in Canada from 2012/2013 to 2014/2015, in Report on the Demographic Situation in Canada. Cat. No. 91-209-X. Ottawa: Statistics Canada. http://www. statcan.gc.ca/pub/91-209-x/2016001/article/14650-eng.htm; retrieved 21 January 2018.

Simard, M. 2009. Retention and departure factors influencing highly skilled immigrants in rural areas: Medical professionals in Quebec, Canada, in International Migration and Rural Areas: Cross-National Comparative Perspectives, edited by B. Jentsch and M. Simard. London: Routledge, p. 43-74.

Sisco, A., and C. Stonebridge. 2010. Toward Thriving Northern Communities. Ottawa: Conference Board of Canada.

Southcott, C. 2013. Globalization and rural change in Canada's territorial north, in Social Transformation in Rural Canada: New Insights into Community, Cultures, and Collective Action, edited by J.R. Parkins and M. Reed. Vancouver: UBC Press, p. 43-65.

Speer, S., and J. Jivani. 2017. The rural/urban divide and a more inclusive Canada. Policy Options (June 5). http://policyoptions.irpp.org/magazines/june-2017/the-urbanrural-divide-and-a-moreinclusive-canada; retrieved 15 January 2018.

Standing Committee on Natural Resources. 2012. Resource Development in Northern Canada. Ottawa: House of Commons. http://publications.gc.ca/collections/collection_2012/parl/XC49-1-1411-04-eng.pdf; retrieved 21 January 2018.

Statistics Canada. 2015. Longitudinal and International Study of Adults (LISA). Ottawa: Statistics Canada. http://www23.statcan.gc.ca/imdb/p2SV.pl?Function=getSurvey\&SDDS=5144; retrieved 31 January 2017.

- 2017a. Population size and growth in Canada: Key results from the 2016 census. The Daily (8 February). Cat. No. 11-001-X.

—. 2017b. Illustrated Glossary, Census Year 2011. Cat. No. 92-195-X. Ottawa: Statistics Canada.

- 2017c. Immigration and ethnocultural diversity: Key results from the 2016 Census. The Daily (25 October). Cat. No. 11-001-X.

—. 2017d. Births and Total Fertility Rate, by Province and Territory. Ottawa: Statistics Canada.

Yoshida, Y., and H. Ramos. 2013. Destination rural Canada: A basic overview of recent immigrants to rural small towns, in Social Transformation in Rural Canada: New Insights into Community, Cultures, and Collective Action, edited by J.R. Parkins and M. Reed. Vancouver: UBC Press, p. 67-87. 